\title{
The Structure of Silicates.*
}

\author{
By Prof. W. L. BraGG, F.R.S.
}

$\mathrm{D}^{\mathrm{u}}$ URING the last few years a number of silicate structures have been analysed by means of $\mathrm{X}$-rays in the Physical Laboratories of the University of Manchester. In the course of these investigations, we have found the atomic arrangement in the olivine, chondrodite, phenacite, pyroxene, and amphibole groups amongst the silicates of divalent metals, and in a number of aluminium silicates such as the forms of $\mathrm{Al}_{2} \mathrm{SiO}_{3}$, staurolite, topaz (analysed also by Pauling), beryl, and the zeolite analcite. Other silicates analysed are titanite, and benitoite containing titanium, danburite containing boron, zircon (analysed also by Vegard) and thortveitite. A group of workers has carried out these analyses, important contributions being made by Warren (pyroxenes and amphiboles), Zachariasen (titanite, thortveitite, benitoite), Naray (staurolite, cyanite), Taylor (forms of $\mathrm{Al}_{2} \mathrm{SiO}_{5}$ and analcite), and West (chondrodite group). Warren has just reported an analysis of the melitite group. In addition, Menzer has analysed the garnet group, and Jaeger the family of compounds to which ultramarine belongs. Preliminary observations have been published by Schiebold on the felspars, and by Mauguin on the composition of the micas. So much ground has been covered that it is possible to review the silicates as a class of compounds, though of course such a survey must be of a very preliminary character.

In the following description, the silicates will be considered in the light of the new knowledge of their atomic arrangement. The conclusions arrived at often reflect well-known and widely accepted views of their nature, but the $\mathbf{X}$-ray analysis has introduced a greater precision and many novel elements.

The distinguishing feature of silicate structures may be described as their intermediate position between salts of acid radicals on one hand, and metallic oxides on the other. We may consider the way in which oxygen is associated in crystal structures with the successive elements magnesium, aluminium, silicon, phosphorus, sulphur, and chlorine. The last three form acid radicals $\left(\mathrm{PO}_{4}\right)^{3-},\left(\mathrm{SO}_{4}\right)^{2-}$, $\left(\mathrm{ClO}_{4}\right)^{1-}$, and these self-contained groups (and also complicated groups such as $\left.\left(\mathrm{S}_{2} \mathrm{O}_{7}\right)^{2-}\right)$ combine with metallic ions to form salts. Silicon also forms selfcontained groups such as $\left(\mathrm{SiO}_{4}\right)^{4-},\left(\mathrm{Si}_{2} \mathrm{O}_{7}\right)^{6-}$, and more complicated forms, which may, if we choose, be considered as acid radicals of the usual type. The novel feature is introduced by its additional power of forming silicon-oxygen complexes with indefinite extension in space. It is this feature which gives rise to the vast variety of silicates and explains the difficulty of assigning chemical formulæ to them as if they were ordinary salts.

The rôle played by silicon in the inorganic world has been compared to that played by carbon in the organic world, but there is an essential difference between them. In organic chemistry the great variety of compounds is due to the possibility of continuing the link between carbon and carbon so as to fcrm more and more complex groups. In the silicates, there often is a similar indefinitely extended linking, but it is always one in which an oxygen atom is inter. posed between two silicon atoms. The extended silicon-oxygen linking is a transition towards the ionic lattices which metals such as magnesium form with oxygen. The passage is the more gradual because aluminium can replace silicon in a siliconoxygen complex, and at the same time can replace a metal such as magnesium. Our very use of the term

* Lecture delivered before the Mineralogical Society on Mar. 18. 'silicate', however, implies a separation of the silicon. oxygen groups in a somewhat arbitrary way from the rest of the structure and a consideration of them as acid radicals, and there is good reason for regarding the silicon-oxygen bond as essentially different from the polar bond in an ionic crystal of metal and oxygen.

In all compounds hitherto analysed, silicon is found at the centre of a regular tetrahedral group of oxygen atoms. The oxygen atoms are about $2 \cdot 6 \mathrm{~A}$. apart, and the oxygen silicon distance is $\mathrm{I} \cdot 6 \mathrm{~A}$. These tetrahedral groups can link together by sharing an oxygen atom. In general, the lower the ratio of oxygen to silicon in a silicate, the greater is the extent to which this linking takes place. In this way, a range of structures is built up with a successive extension in space of the silicon-oxygen linking, represented at one end by the orthosilicates with independent groups $\left(\mathrm{SiO}_{4}\right)^{4-}$, and at the other end by the forms of silica such as quartz which W. H. Bragg and Gibbs first showed to be a structure of linked tetrahedra where every oxygen atom is shared by two silicon atoms.

We can distinguish the following forms of siliconoxygen complex :

(a) Orthosilicates.--Independent groups $\left(\mathrm{SiO}_{4}\right)^{4-}$.

(b) Self-contained Groups. - These are formed by linking a finite number of tetrahedral groups. Examples are $\left(\mathrm{Si}_{2} \mathrm{O}_{7}\right)^{6-},\left(\mathrm{Si}_{3} \mathrm{O}_{9}\right)^{6-},\left(\mathrm{Si}_{4} \mathrm{O}_{12}\right)^{8-},\left(\mathrm{Si}_{6} \mathrm{O}_{33}\right)^{22-}$. The latter three groups are formed by linking three, four, or six tetrahedral groups in a ring (the sixfold ring in beryl is a striking example).

(c) Silicon-Oxygen Chains.--In the pyroxenes there is a simple chain of tetrahedral groups, each sharing an oxygen atom with its neighbours on either side, and thus leading to a composition represented by $\left(\mathrm{SiO}_{3}\right)^{2-}$. It is interesting to note that this linking found by Warren and the author was predicted shortly before by Machatschki. In the amphiboles two such chains are joined side by side by a further sharing of oxygen atoms or 'condensation', leading to a composition $\left(\mathrm{Si}_{4} \mathrm{O}_{11}\right)^{6-}$. These chains in the pyroxenes and amphiboles (and probably other types of chain in other compounds) lie side by side. They are like acid radicals with indefinite extension in one dimension, and are bound together by the metallic ions. They are parallel to the fibre direction in the fibrous forms which these compounds often assume.

(d) Silicon-Oxygen Sheets.-If three oxygen atoms of each tetrahedral group are shared, the resulting ratio will be represented by $\left(\mathrm{Si}_{2} \mathrm{O}_{5}\right)^{2-}$. No compounds of this type have yet been analysed, but it is interesting to note two features. The most direct way of linking tetrahedral groups into sheets leads to an arrangement which has hexagonal symmetry, and the dimensions of the network are precisely those of the basal plane of mica (measured by Mauguin). It may be that such sheets will be found to form the basis of the scaly minerals, such as mica, chlorite, and talc, which have a marked basal cleavage and pseudohexagonal structure.

(e) Three-dimensional Silicon-Oxygen Networks.-If every oxygen of the tetrahedral groups is shared between two silicon atoms, the structure will be silica, $\mathrm{SiO}_{2}$. Machatschki first pointed out that if a certain proportion of the silicon were replaced by aluminium, the result would be a silica-like arrangement of linked tetrahedra which had a total negative charge, and into which in consequence metallic cations could be incorporated. This is the essential feature of ultramarine and the zeolites, and according to Schiebold 
of the felspars. In some zeolites the ratio of aluminium to silicon is quite low, so we have justification for describing these structures as having acid radicals with endless extension in three dimensions. The bearing of this on the ease with which the water content is changed and metallic ions substituted in the zeolites without breaking down a crystal, is obvious.

These silicon-oxygen complexes are bound together by metallic ions, which fit into the spaces between the large oxygen atoms. The way in which the cations are incorporated is very interesting. I first pointed out the prevalence in silicate structures of close-packed regular groups of oxygen atoms, as if many cations such as $\mathrm{Be}^{*}, \mathrm{Al}^{\cdots}{ }^{\cdots}, \mathrm{Mg}^{*}, \mathrm{Fe}{ }^{\cdots}$, $\mathrm{Ti}^{\cdots}$. ftted into close-packed groups of four oxygen atoms at the corners of a tetrahedron, or six at the corners of an octahedron, with little distortion. Larger ions such as $\mathrm{K}^{*}, \mathrm{Ca}^{*}, \mathrm{Na}$ ' have often more oxygen atoms round them, and the group is distorted. This is natural, for while four or six spheres packed together assume a regular tetrahedral or octahedral form, eight spheres can be packed together more compactly by a less regular arrangement than that at the corners of a cube. In the next place, these metallic ions appear to be attracted to the oxygen atoms which have only one link to silicon. Oxygen atoms linked to two silicon atoms have little external field, as if their valency were saturated. It is very likely, as Lowry has insisted, that we must regard the silicon-oxygen link as wholly or partly a homopolar bond. Oxygen atoms with a single bond to silicon behave as if they had a single charge - e, those with a double bond as if they were uncharged. Another very important principle enters, which Pauling was the first to point out, in a general treatment of ionic compounds. The metallic atoms are so incorporated into the structure that there is a local balancing of electric charge between cations and the negatively charged oxygen atoms.
These features are beautifully illustrated by models of silicate structures.

West and myself, in a paper on the structure of certain silicates in 1927, directed attention to the importance of oxygen in silicate formulce. Oxygen atoms cannot be removed from the structure without breaking up the regular groups, and in most cases, owing to their relatively large size, additional oxygen atoms cannot be incorporated in the unit cell. This applies not only to the oxygen atoms which are linked to silicon, but also to additional ions $\mathrm{O}^{\prime \prime}, \mathrm{OH}^{\prime}, \mathrm{F}^{\prime}$ which are part of the structure, the latter ions taking up the same space as oxygen. On the other hand, Al can replace $\mathrm{Si}$ or $\mathrm{Mg}, \mathrm{Mg}, \mathrm{Fe}$, and $\mathrm{Mn}$ are interchangeable, Ca can replace $\mathrm{Na}$, and so forth, in the familiar way. Hence in giving the atomic composition of a silicate after a chemical analysis has been made, the relative numbers of the constituents must be so expressed that the absolute number of oxygen atoms is correct for that particular type of crystal. This immensely simplifies the problem of composition in such substances as the silicates where isomorphous replacement is so frequent. Mauguin's work on the micas, Warren's on the amphiboles, and Berman's study of the melitite group, afford examples. The relatively large size of oxygen, and the constancy with which a distance of about $2 \cdot 7 \mathrm{~A}$. between oxygen centres appears in the silicate structures, make it convenient to think of the silicates as based on an oxygen framework which determines their dimensions, a fact of which considerable use was made in the earliest analyses.

Although so little ground has been covered, we can begin to see the general lines on which this interesting class of inorganic compounds is based. The technique of X-ray analysis has reached a stage where the complexity of the structure is no barrier, for examples already worked out are as complex as any we are likely to encounter.

\section{A Large Power Plant at Billingham-on-Tees.}

$\mathrm{T}$ a paper read to the Institution of Electrical Engineers on Mar. 13, H. A. Humphrey, D. M. Buist, and J. W. Bansall gave a complete description of the new industrial power plant which has been erected by Imperial Chemical Industries, Ltd., for the factory at Billingham-on-Tees belonging to Synthetic Ammonia and Nitrates, Ltd. The conditions governing the design of this power plant differ from those relating to a public electricity supply station. The extension programme required nearly 7000 tons of steam per day for process purposes as well as 37,500 kilowatts of electrical power. The quantity of steam required for process purposes is double that required to generate the electrical energy. Hence the boiler plant capacity had to be made three times as great as if electrical power only had been required.

Chemical works have an almost constant load; in technical language, their load factor is a hundred per cent and continuity of supply is of vital importance. A cessation of power would not only cause a loss of output, but would also upset the steady conditions of temperatures and pressures on which the satisfactory operation of the plant depends. The power plant, therefore, must have a sufficient stand-by plant and means for bringing that plant rapidly into operation. Everything has to be considered on the lines of 'safety first'. As the output of the plant has to be as great as that of the largest electricity station in Great Britain, great attention was paid to securing economy in the generating costs.

It was considered that $856^{\circ} \mathrm{F}$. was the highest safe temperature for ordinary steel superheaters, as a great deal has yet to be learned about ' creep' stresses at this temperature. Considerations of safety, therefore, led the designers to adopt a maximum boiler pressure of $815 \mathrm{lb}$. per square inch. As high pressure boilers must have distilled water feed, and as only sixty per cent of the necessary supply could be obtained from the condensed steam, 2500 tons of water have to be distilled every day to add to the "make up 'feed.

By passing the total amount of steam generated, including that required for process purposes, 23,800 kilowatts are obtained. Two turbo-alternators, each of 12,500 kilowatts, provide the working units, and one is added as a reserve. It was stated that the estimated cost of the electric energy generated in the station is well below the cost of any electric generating station in the world depending on coal as fuel. This is attributed to the use of the high pressure and high temperature steam. The primary turbines pass a greater quantity of steam than would be available in an ordinary power station. Owing to the locality, the coal is cheap, and there is an abundant supply of cooling water. The load factor also is the highest possible.

An ingenious method of supplying the two boiler and pulveriser buildings is adopted. The raw coal is brought in by rail and dropped into underground bunkers, from which it is raised by hoists to overhead belt conveyors. It is thus carried to overhead steel bunkers in the pulveriser house, where it falls through chutes to the weighers and thence to the mill hoppers,

No. 3152, VoL. 125] 